\title{
Prevalence of Alcohol use Disorder among Prisoners in Ambo Town, West Shewa Zone, Oromia Regional State, Ethiopia, 2019
}

\author{
Takele Tiki $^{1 *}$, Kassa mamo ${ }^{2}$, KafyalehuTaye ${ }^{3}$, Belete feyera ${ }^{4}$ \\ ${ }^{1}$ Ambo University College of medicine and health science department of Psychiatry Nursing, Ambo, Ethiopia \\ ${ }^{2}$ Ambo University College of medicine and health science department of midwifery, Ambo, Ethiopia \\ ${ }^{3}$ Ambo University College of medicine and health science department of Public health, Ambo, Ethiopia \\ ${ }^{4}$ Ambo University College of medicine and health science department of Nursing, Ambo, Ethiopia
}

*Corresponding author: Takele Tiki, Ambo University College of medicine and health science department of Psychiatry Nursing, Ambo, Ethiopia.

Received date: March 14, 2020; Accepted date: May 19, 2020; published date: June 24, 2020

Citation: Takele Tiki, Kassa mamo, KafyalehuTaye, Belete feyera, Prevalence of Alcohol use Disorder among Prisoners in Ambo Town, West Shewa Zone, Oromia Regional State, Ethiopia, 2019. J Clinical Research and Reports, 4(5); DOI:10.31579/2690-1919/077

Copyright: () 2020: Takele Tiki. This is an open access article distributed under the Creative Commons Attribution License, which permits unrestricted use, distribution, and reproduction in any medium, provided the original work is properly cited.

\begin{abstract}
Background: Alcohol is a psycho active, toxic and potentially addictive substance. It is a causal factor in over 60 diseases and injuries and accounted for $6.4 \%$ of all deaths in the world and the prevalence of alcohol use disorder in the prisoner population to be higher than in the general population.

Objective: To determine the prevalence of alcohol use disorder among prisoners at Ambo town, west shoa zone, Oromia regional state, Central Ethiopia, 2019

Method: An institutional based cross-sectional study was conducted in Ambo town by using systematic random sampling method, from sample of 345 prisoners by using self-reporting questionnaire (SRQ) interview by using AUDIT questionnaire. Simple random sampling was use to select number of prisoners. Data was checked for completeness and any incomplete information were excluded from the entry. The study was conducted after a letter of permission from Ambo university send to Ambo town general prison.

Conclusion: The high prevalence of AUDs detected in our facility-based survey of Ambo town prisoners implies the need to design effective screening tools and feasible interventions for AUDs. This study found a high prevalence of alcohol use disorder among prisoners in a correctional institution in Ambo town, central Ethiopia, in the 12 months before imprisonment. The most commonly used was alcohol, followed by khat, nicotine, and shishas. Generally, despite the increased morbidity of alcohol users and unpleasant psychosocial consequences of this habit, most prisoners reported not receiving treatment prior to imprisonment.
\end{abstract}

Key words: prevalence; alcohol use disorders; Ambo prisoners; Ambo; Central Ethiopia

\section{Background}

Alcohol is a psychoactive, toxic and potentially addictive substance (Babor $\mathrm{T}$ et al 2010).The WHO estimates that around 2 billion people worldwide consume alcohol (WHO 2004) a. It is apparent though that drinking is influenced by factors such as genetics, social environment, culture, age, gender, accessibility, exposure and personality. The relationship between alcohol and crime is, therefore, not a simple causal one. For instance, with regard to violence, alcohol is recognized as both a causal (Boden J, Fergusson DM, Horwood LJ 2012) as well as a contributory factor (WHO 2005). Specific pharmacological effects can affect an individual's behavior and judgment (Ramstad M 1950-2003). Not all alcohol consumption, however, leads to violence and not all violence is due to alcohol. There is a complex interplay between the quantity of alcohol consumed, drinking patterns, and individual and contextual factors. Links between alcohol and violence appear to be stronger in countries where drinking is characterized by acute intoxication, such as in northern European countries (WHO 2005).Alcohol has been found to be a factor in half of all violent crimes [Flatly, J., et al 2009/10]. In England and Wales alcohol-related crime is estimated to cost society $£ 11$ billion (2010-2011 costs) [Alcohol Team Home Office 2013]. However the precise relationship is complex [Plant, M., M. Plant, and C. Thornton, People and places 2002], with an intricate interplay between drinking patterns, the amount of alcohol consumed and individual and contextual factors [Graham, L., et al 2012].

A national study of prisoners and parolees in 1996 found that just under half had taken alcohol or other drugs just prior to the crime for which they were incarcerated (Rocha-Silva \&Stahmer, 1996).Drinking was especially linked to rape and housebreaking offences. Regarding violent offences, arrestees indicated that they were under the influence of alcohol for $25 \%$ of weapons related offences, $22 \%$ of rapes, $17 \%$ of murders, $14 \%$ of assault cases and $10 \%$ of robberies. Levels of alcohol-related crime were particularly high for family violence offences at $49 \%$, of arrestees also indicated that they were often under the influence of alcohol in cases involving property offences, for example, $22 \%$ of cases involving housebreaking and $12 \%$ of cases involving the theft of a motor vehicle. When asked why they consumed alcohol or other drugs in relation to crimes, many arrestees indicated they consumed these substances in order to give them courage to commit the crimes (Parry et al., 2004). Alcohol 
and illicit drug use account for $5.4 \%$ of the world's annual disease burden, with tobacco responsible for $3.7 \%$ (WHO 2010).It is a causal factor in over 60 diseases and injuries and accounted for $6.4 \%$ of all deaths in the European region in 2004 (Rhem J et al 2009). The prevalence of alcohol problems in prisoners is high, although the evidence base to date is limited, an international systematic review found that $18-30 \%$ of men and $10-24 \%$ of women prisoners had alcohol problems, but the studies were noted to be heterogeneous (Fazel S, Bains P, Doll H 2006). In the United Kingdom (Scotland) in 2011, 50\% of prisoners reported that they were drunk at the time of their offences, an increase of $10 \%$ over the previous 5 years (Carnie J, Broderick R. Scottish Prisoner Survey 2011

Next to caffeine, alcohol is the second most commonly used psychoactive substance globally. However, as alcohol has an initial high concentration of acetaldehyde in the brain, symptoms of intoxication and deterioration of behavior was mostly ensue immediately in the drinker (Alcohol and mental health 2007; Sadock\&Sadock 2007:394). When alcohol is continually used not only do physiological changes occur in the brain and nervous system, but psychologically the person can have an increased tendency towards addiction. Harmful drinking is a major determinant for neuropsychiatric disorders such as alcohol use disorders, epilepsy and other non-communicable diseases, for example, cardiovascular diseases, cirrhosis of the liver as well as some types of cancers (Alcohol 2013; WHO 2011:22).

Worldwide, A systematic international review found that $18-30 \%$ of men and $10-24 \%$ of women had alcohol problems defined as "alcohol abuse/dependence" (Fazel S, Bains P, Doll H 2006),In most European countries, the drinking of alcohol is common in the adult population, with 80-95\% drinking at least occasionally (. Fazel S, Bains P, Doll H 2006). In the United Kingdom (Scotland) in 2011, 50\% of prisoners reported that they were drunk at the time of their offences, an increase of $10 \%$ over the previous 5 years ( Rutherford M, Duggan S 2009). Nearly half (48\%) said they would accept help for their alcohol problems if it was offered in the prison. Further Scottish research found that $73 \%$ of prisoners had an alcohol-use disorder, with $36 \%$ possibly being alcohol-dependent (Parkes T et al 2011).

The prevalence of alcohol problems is markedly higher in the Scottish prison population compared to the general population, at all ages and for both women and men, as shown in comparative analysis conducted as a separate part of this study [Parkes T, MacAskill S et al 2011].

In a survey of prisoners in Australia , hazardous and harmful drinking levels were reported to be $57 \%$ and $18 \%$, respectively, among male prisoners compared to $49 \%$ and $13 \%$, respectively, among females according to AUDIT scores(Jones GY. Hoffmann NG 2006)). In another study of a relatively small sample $(n=47)$, it was found that up to $60 \%$ of French male prisoners were positive for alcohol problems (scoring $8+$ on AUDIT), with a higher prevalence when screening was conducted two weeks into their sentences rather than at the start (Parkes T et al 2011).

There is no study conducted in Ethiopia among prisoners, this study will be used as a baseline information for those who wants to do their research on this related topic, may aid to develop strategies for improvement of interventions on alcohol use in prisoners and this study was an input for investigation and identification of alcohol use health problems who living in the correctional areas or prison.

\section{Method}

An institutional based cross-sectional study design was used.

\section{Study setting}

Ambo general prison is located in Ambo town which is the capital town of West Shoa Zone of Oromia Region, Ethiopia; which is located approximately $114 \mathrm{~km}$ far from Finfinne to the Western direction. West Shoa is bordered on the south by South- West Shoa Zone and Jima Zone, on the North by the Amhara region and on the East by Finfinne special Zone and on West by HoroGuduruWollega Zone and East Wollega Zone. Ambo Prisons was established since 1940 Ec. The total prisoned during interview we did1856 (males $=1802$ and females $=56$ )

\section{Sample size determination}

The formula that we have used to calculate sample size in the study was

$n=\frac{\left[z \frac{\alpha}{2} \sqrt{p(1-p)}\right]^{2}}{d^{2}}$

Where $\mathrm{d}=$ margin of error

$\mathrm{n}=$ sample size

$\mathrm{Z}=$ calculated number from $\mathrm{Z}$-table

$\mathrm{P}=$ point estimate $=$ we take $50 \%$ because there is no prevalence point estimate value in Ethiopia, and other East African countries

The sample size is calculated by using the formula for population proportion at confidence interval $\mathrm{CI}=95 \%$, at $95 \%+1.96$, and margin of error $=5 \%$

$n=\frac{\left[z \frac{\alpha}{2} \sqrt{p(1-p)}\right]^{2}}{d^{2}}=(1.96 \times 1.96(0.5 \times 0.5)) \div(0.05 \times 0.05)$

$=385$ and $10 \%$ of participant are non-respondent $=424$

$\mathrm{n}=424$ Since our study populations less than 10,000 it is finite we can $\mathrm{N}=1858$

$$
n=\frac{n_{o}}{1+\frac{n_{0}}{N}}==424 / 1+424 / 1856=345
$$

345= Final sample size

\section{Data collection instruments}

The AUDIT first three questions (1-3) explore quantity and frequency of alcohol consumption (Hazardous Alcohol Use), the second three questions (4-6) explore signs of alcohol dependency and the last four questions (7-10) explore Alcohol-related problems (harmful alcohol use). Each question has a response category that ranges from 0 to 4 , with the first response for each question scoring 0 (never), the second scoring 1 (less than monthly), the third scoring 2 (monthly), the fourth scoring 3 (weekly), and the last response scoring 4 (daily or almost daily). For questions 9 and 10, which only have three responses, the scoring is 0,2 and 4 (from left to right). To determine how many standard drinks of alcohol the patients took, question number two is modified to "Type of alcohol" and "Its amount". The response was converted to standard drinks. In accordance with the recommended scoring, a total AUDIT score of eight or more was used to define probable ,alcohol use disorder ${ }^{\text {re }}$. A total AUDIT score of 1-7 indicated social drinking, a score of 8-15 indicated "hazardous drinking" a score of 16-19 indicated "harmful drinking" and a score of 20 or above indicated probable alcohol dependence. The total AUDIT score, alcohol consumption level, signs of dependence, and markers of present harm should all play a role in 
determining how to manage a patient with AUD (Luchters S, Geibel S, Syengo M, Lango D, King'ola N, et al. 2011)

Ethical clearance was obtained from the Ethical Review Committee of Ambo University, College of medicine and health sciences. The study participants were free to enroll in the study and withdraw from it at any time. All the interviews with participants were made with strict privacy after getting informed consent from the participants and assuring confidentiality. Every information accessed in due course was confidentially kept. Patients with AUD were referred to psychologists in the prisoners' clinic.

\section{Result}

A total of 345 Ambo town prisoners were approached for enrolment in the study. Of the total Study sample 337 agreed to participate resulting in a response rate of $97.68 \%$. The majority $330(97.9 \%)$ of the respondents were males, Oromo $293(86.94362 \%)$

By ethnicity and followers of orthodox religion $175(51.92878 \%)$ followed by protestant Church followers 71(21.06825\%), waaqeffataa $55(16.32047 \%)$ and Muslim followers 36(10.68249\%). The age of the respondents was mainly between $25-34$ years 258 (76.55786\%). With regards to educational status majority $239(70.91988 \%)$ had one or more grades at primary school and $254(75.37 \%)$ reported mean family income of less than 1500 birr per month. At the time of the study, $121(35.91 \%)$ of the respondents were married followed by singles $204(60.53 \%)$ and $293(86.94 \%)$ of the overall respondents were unemployed. The vast majority $215(63.80 \%)$ of them were living with their family (detail showed by table).

\begin{tabular}{|c|c|c|c|}
\hline Variables & Category & Frequency & $(\%)$ \\
\hline \multirow[t]{2}{*}{ Gender } & Male & 330 & 97.9 \\
\hline & Female & 7 & 2.1 \\
\hline \multirow[t]{5}{*}{ Age in years } & $18-24$ & 258 & 76.6 \\
\hline & $25-34$ & 29 & 8.6 \\
\hline & $35-44$ & 14 & 4.2 \\
\hline & $45-70$ & 33 & 9.8 \\
\hline & $>70$ & 3 & 0.9 \\
\hline \multirow[t]{4}{*}{ Ethnicity } & Oromo & 293 & 86.9 \\
\hline & Amhara & 19 & 5.6 \\
\hline & Gurage & 9 & 2.7 \\
\hline & Othes & 16 & 4.7 \\
\hline \multirow[t]{4}{*}{ Religion } & Orthodox & 175 & 51.9 \\
\hline & Protestant & 71 & 21.1 \\
\hline & Waaqeffataa & 55 & 16.3 \\
\hline & Muslim & 36 & 10.7 \\
\hline \multirow{4}{*}{ Educational status } & Un educated & 55 & 16.3 \\
\hline & Primary & 105 & 31.2 \\
\hline & Secondary & 134 & 39.8 \\
\hline & College/university & 43 & 12.8 \\
\hline \multirow{3}{*}{ Occupation } & Un employed & 230 & 68.2 \\
\hline & Government employed & 36 & 10.7 \\
\hline & Others & 71 & 21.1 \\
\hline \multirow[b]{2}{*}{ Mean Family monthly income } & $<1500 \mathrm{EBR}$ & 254 & 75.4 \\
\hline & $>1500 \mathrm{EBR}$ & 83 & 24.6 \\
\hline \multirow{3}{*}{ Marital status } & Single & 204 & 60.5 \\
\hline & Married & 121 & 35.9 \\
\hline & Other & 12 & 3.6 \\
\hline \multirow[t]{3}{*}{ Living arrangement } & Alone & 103 & 30.6 \\
\hline & With family & 215 & 63.8 \\
\hline & With relatives & 19 & 5.6 \\
\hline
\end{tabular}

Table: - Alcohol Use Disorders among ambo town prison west shewa zone Oromia region, Ethiopia.

\section{Discussion}

In our current study the overall prevalence of AUDs (13.4\%), defined by an AUDIT score $\geq 8$, was substantially higher than that found in community-based studies carried out in Addis Ababa and Butajira, Ethiopia 2.7\% and 3.7\%, respectively [Kebede D, Alem A (1999).] A
South African study conducted in primary care clinic showed AUDs prevalence of $17.6 \%$ [Ward CL, Mertens. (2008)]. A population based study conducted in Thailand and Singapore the prevalence of AUDs was $10.9 \%$ and $3.6 \%$ respectively [Junsirimongkol B, Kittirattanapaiboon P, Khamwongpin M, Chutha W, Kongsuk T, et al. (2011)]. This may be due to the difference between tools used in this study (AUDIT vs. CAGE), as 
the CAGE is designed to detect more severe AUDs and the difference in the study community. The prevalence of alcohol dependence found in our study was higher than theresult from a review of problem drinking in Ethiopia (1.0\%) [39. Kebede D, Alem A (1999).]The estimated prevalence rate of AUD was $13.4 \%$, with $6.84 \%$ harmful drinking, 3.87 $\%$ hazardous drinking, and $2.67 \%$ alcohol dependence.

\section{Abbreviations}

AAD-Alcohol abuse or dependency

AUDIT- Alcohol use disorder identification test

AUDs-Alcohol use disorders

AU-Ambo University

DAD- Drug abuse dependency

DWI-Driving while intoxication

SRQ- Self reporting questionnaires

\section{Declarations}

\section{Ethics approval and consent to participate}

The study proposal was initially approved by the ethical review board of Ambo University. A formal letter of permission was obtained from the college. The information about the study was given to the participants. Verbal and then written informed consent was sought from each participant who agreed to participate in the study and full filled the inclusions criteria. Only anonymous data collected in private rooms.

\section{Availability of data and materials}

This study is a part of institutional based a descriptive cross sectional study among Ambo town prisons. The dataset pertaining to this study will be shared upon reasonable request.

\section{Conflict of Interests}

The authors declare that they have no competing interests.

\section{Authors' contributions}

Takele T. has involved in the conception, design, analysis, data interpretation and report writing. Kassa M. has involved in editing all part of activities.

Kefyalehu T. All of us read and approved the final manuscript. Belete F. all of us read and approved the final manuscript

\section{Acknowledgements}

We would like to acknowledge Ambo University College of Medicine and Health Science for funding this study, In addition, we would like to thank data collectors and study participants.

\section{References}

1. Alcohol and interpersonal violence policy briefing.Copenhagen, WHO Regional Office for Europe, 2005 (accessed 27 September 2012).

2. Alcohol Team Home Office, Next steps following the consultation on delivering the Government's alcohol strategy. 2013: London.

3. American Psychological Association (APA). "How Therapy Helps: Understanding Alcohol Use Disorders and Their Treatment, Psychologists play a vital role.” December 2001.

4. Babor T et al. Alcohol: no ordinary commodity. Oxford, Oxford University Press, 2010.

5. Bland RC, Newman SC, Dyck RJ, Om H. Prevalence of psychiatric disorders and suicide attempts in a prison population.Cdan Journal of Psychiatry 1990; 35:407413.
6. Boden J, Fergusson DM, Horwood LJ. Alcohol misuse and violent behavior: findings from a 30-year longitudinal study. Drug and Alcohol Dependence, 2012, 122:135-141.

7. Butler $\mathrm{T}$ et al. Drug use and its correlates in an Australian prisoner population. Addiction Research and Theory, 2003, 11(2):89-101.

8. Bureau of Justice Statistics.Prisoners in 2003. NJC Pub. No. 205335. Washington, DC: U.S. Department of Justice, Bureau of Justice Statistics, 2004.

9. Bureau of Justice Statistics.Probation and Parole in the United States, 2003. NJC Pub. No. 205336. Washington, DC: U.S. Department of Justice, Bureau of Justice Statistics, 2004.

10. Carnie J, Broderick R. Scottish Prisoner Survey 2011. Edinburgh, Scottish Prison Service, 2011.

11. European Information System on Alcohol and Health [web site]. Geneva, World Health Organization, 2010.

12. European status report on alcohol and health. Copenhagen, WHO Regional Office for Europe, 2010.

13. Fazel S, Bains P, Doll H. Substance abuse and dependence in prisoners: a systematic review. Addiction, 2006, 1:181-191

14. Flatley, J., et al., Crime in England and Wales 2009/10. 2010, Home Office: London.

15. Jones GY. Hoffmann NG. (2006), Alcohol dependency; international policy implication for prison population .Subst Treat prev policy 1:33

16. Galassi A, Mpofu E, Athanasou J. Therapeutic community treatment of an inmate population with substance use disorders: post-release trends in re-arrest, re-incarceration, and drug misuse relapse. Int $\mathbf{J}$ Environ Res Public Health. 2015; 12:7059-72.

17. Graham K, West P 2001. Alcohol and crime: Examining the risk. In: Heather H, PetersTJ, Stockwell T. Chichester (eds). International Handbook of Alcohol Dependence and problems. England, John Wiley and Sons Ltd, pp: 439-470.

18. Graham, L., et al., Alcohol problems in the criminal justice system: an opportunity for intervention. 2012, World Health Organization: Regional Office for Europe: Denmark.

19. Graham L. Prison health in Scotland: a health care needs assessment. Edinburgh, Scottish Prison Service, 2007.

20. Junsirimongkol B, Kittirattanapaiboon P, Khamwongpin M, Chutha W, Kongsuk T, et al. (2011)

21. Kaner, E., D. Newbury-Birch, and N. Heather, Brief Interventions, in Evidence-based Addiction Treatment, P. Miller, Editor. 2009, Elsevier: San Diego, California. -

22. Knight, K.; Simpson, D.D.; and Hiller, M.L. Screening and referral for substance-abuse treatment in the criminal justice system. In: Leukefeld, C.G.; Tims, F.; and Farabee, D.; eds. Treatment of Drug Offenders: Policies and Issues. New York: Springer, 2002. pp. 259-272.

23. Kebede D, Alem A (1999). The epidemiology of alcohol dependence and problem drinking in Addis Ababa, Ethiopia. ActaPsychiatrScandSuppl 397: 30-34. 40. Alem A, Kebede D, Kullgren G (1999).The epidemiology of problem drinking in Butajira, Ethiopia. ActaPsychiatrScandSuppl 397: 77-83.

24. Lapham, S.C.; Smith, E.; C'de Baca, J.; et al. Prevalence of psychiatric disorders among persons convicted of driving while impaired. Archives of General Psychiatry 58:943-949, 2001. 27. Lapham, S. Screening and brief intervention in criminal justice settings. Alcohol Research \& Health 28(2):85-93, 2004/2005

25. Luchters S, Geibel S, Syengo M, Lango D, King'ola N, et al. (2011) 
26. MacAskill $\mathrm{S}$ et al. Assessment of alcohol problems using AUDIT in a prison setting: more than an 'aye or no' question. BMC Public Health, 2011, 11:865.

27. Math SB, Murthy P, Parthasarathy R, Naveen Kumar C, Madhusudhan S 2011. Mental health and substance use problems in prisons: Local lessons for national action. Publication, National Institute of Mental Health Neuro Sciences, Bangalore

28. Marzano L et al. Psychosocial influences on prisoner suicide: a case-control study of near-lethal self-harm in women prisoners. Social Science \& Medicine, 2011, 72(6):874-883.

29. Narkauskaite L, Juozulynas A, Mackiewicz Z, Surkiene G, Prapiestis J. The prevalence of psychotropic substance use and its influencing factors in Lithuanian penitentiaries. Med SciMonit 2007; 13: CR131-135

30. Newbury-Birch D et al. Sloshed and sentenced: a prevalence study of alcohol use disorders among offenders in the North East of England. International Journal of Prisoner Health, 2009
31. O'Driscoll C, Samuels A, Zacka M. Suicide in New South Wales Prisons, 1995-2005: towards a better understanding. Australia and New Zealand Journal of Psychiatry, 2007, 41(6):519-524.

32. Parkes $\mathrm{T}$ et al. Prison health needs assessment for alcohol problems. Edinburgh, NHS Health Scotland, 2011.

33. Parkes $\mathrm{T}$ et al. Prison health needs assessment for alcohol problems. Edinburgh, NHS Health Scotland, 2010.

34. Parkes T, MacAskill S, Brooks O, Jepson R, Atherton I, Doi L, McGhee S, Eadie D: Prison health needs assessment for alcohol problems NHS Health Scotland; 2011

35. Parry, C.D.H., Plüddemann, A., Louw, A., \& Leggett, T. (2004). The 3-Metros Study of Drugs and Crime in South Africa: Findings and policy implications. American Journal of Drug \& Alcohol Abuse, 30, 167-185.

36. Plant, M., M. Plant, and C. Thornton, People and places: Some factors in the alcohol violence link. Journal of Substance Use, 2002. 7: p. 207-213.

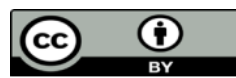

This work is licensed under Creative Commons Attribution 4.0 License

To Submit Your Article Click Here: Submit Article

DOI: $10.31579 / 2690-1919 / 077$
Ready to submit your research? Choose Auctores and benefit from:

*ast, convenient online submission
rigorous peer review by experienced research in your field
rapid publication on acceptance
* authors retain copyrights
* imique DOI for all articles

At Auctores, research is always in progress.

Learn more www.auctoresonline.org/journals/journal-of-clinicalresearch-and-reports 